\title{
Controlling of Pressure Sensitive Adhesive Properties by Blending Poly(vinylidene fluoride-co-hexafluoro acetone) into Poly(ethylacrylate) Adhesive
}

\author{
Yoshihisa Kano, Noriko Sato, and Saburo AkIYama* \\ Research Laboratory, LINTEC Corporation, \\ 5-14-42, Nishiki-cho, Warabi-shi, Saitama 335, Japan \\ * Laboratory of Chemistry, Faculty of General Education, \\ Tokyo University of Agriculture and Technology, \\ 3-5-8, Saiwai-cho, Fuchu-shi, Tokyo 183, Japan
}

(Received April 17, 1991)

\begin{abstract}
The pressure sensitive adhesive (PSA) properties of the poly(ethyl acrylate) (PEA)/poly(vinylidene fluoride-co-hexafluoro acetone) [P(VDF-HFA)] blends were investigated with blend compositions of $\mathrm{P}(\mathrm{VDF}-\mathrm{HFA})$ contents from 0 to $50 \mathrm{wt} \%$. PSA properties, such as $180^{\circ}$ peel adhesion, J. Dow ball tack and probe tack, decreased with increasing P(VDF-HFA) content, whereas holding power increased. The effects of the morphology, critical surface tension $\gamma_{\mathrm{C}}$ and dynamic mechanical properties on the PSA properties of the PEA/P(VDF-HFA) blends were also investigated. The morphology and $\gamma_{C}$ values were changeless in blends with P(VDF-HFA) contents varied from 0 to $50 \mathrm{wt} \%$ region. On the other hand, dynamic mechanical properties, such as the storage modulus $G^{\prime}$, loss modulus $G^{\prime \prime}$ and glass transition temperature $T_{\mathrm{g}}$ increased monotonically with increasing P(VDF-HFA) content in the blends. Therefore, it was expected that PSA properties in PEA blends could be controlled with P(VDF-HFA) contents in relation to $G^{\prime}$, $G^{\prime \prime}$ and $T_{\mathrm{g}}$ properties.

KEY WORDS Poly(ethyl acrylate) / Poly(vinylidene fluoride-co-hexafluoro acetone)/Blend / Pressure Sensitive Adhesive Properties/Morphology / Critical Surface Tension / Dynamic Mechanical Properties / Storage Modulus / Loss Modulus / Glass Transition Temperature /
\end{abstract}

In recent years, pressure sensitive adhesives composed of polyacrylates as a main component have been successfully utilized in the field of packaging, printing, medical taping, electrical insulation and automobile industry. ${ }^{1-3}$ In general, PSA properties have been controlled by the blending of dissimilar polymers, molecular weight, copolymerization with polar monomer and curing systems. ${ }^{2}$

The poly(ethylacrylate) PEA has been utilized as the main component of PSA, because of its low $T_{\mathrm{g}}\left(\approx-20^{\circ} \mathrm{C}\right)$ and high flexibility at room temperature. In the last decades, the poly(vinylidene fluoride-co-hexafluoro acetone) P(VDF-HFA) having the excellent properties, such as non-tackiness, water repellent, heating and chemicals, was investigated as to the micro-structures ${ }^{4}$ and the miscibility with the various polymers. ${ }^{5-7}$ $\mathrm{We}^{8-13}$ confirmed that the surface segregation of the P(VDF-HFA) occurred in poly(2-ethyl hexyl acrylate-co-acrylic acid-co-vinyl acetate) $\mathrm{P}(2 \mathrm{EHA}-\mathrm{AA}-\mathrm{VAc}) / \mathrm{P}(\mathrm{VDF}-\mathrm{HFA})$ blends.

In this study, we took note of the PEA and the P(VDF-HFA) having the tackiness and non-tackiness, respectively. Then, $180^{\circ}$ peel adhesion, J. Dow ball tack, probe tack and holding power as PSA properties were measured in the blends of PEA/P(VDF-HFA) with the contents of $\mathrm{P}(\mathrm{VDF}-\mathrm{HFA})$ varied from 0 to $50 \mathrm{wt} \%$ region.

It is well-known that the PSA properties were 
affected by the dynamic mechanical properties, the surface tension and the morphology of the bulk. ${ }^{14-16}$ The theoretical approaches to the PSA properties have been also performed with the surface tension and dynamic mechanical properties. ${ }^{17,18}$

In this article, the PSA properties of the PEA/P(VDF-HFA) blends are examined by the above mentioned surface morphology observed with scanning electron microscopy (SEM), the critical surface tension $\gamma_{C}$ and the dynamic mechanical thermal analysis.

\section{EXPERIMENTAL}

\section{Materials}

The PEA was prepared by solution polymerization technique at $70^{\circ} \mathrm{C}$ for $8 \mathrm{~h}$ using benzoyl peroxide as an initiator in the mixture solvent of ethyl acetate $(95 \mathrm{wt} \%)$ with toluene $(5 \mathrm{wt} \%)$. The molecular characteristics of PEA are $M_{n}=46700$ and $M_{w} / M_{n}=6.68$. The P(VDF-HFA) $\left(M_{n}=52000, M_{w} / M_{n}=2.50,8\right.$ (mol\%) HFA) was supplied by Central Glass Co., Ltd. The blends of PEA with P(VDFHFA) were prepared by coating with $20 \mathrm{wt} \%$ THF solution onto poly(ethylene terephthalate) (PET) film of $50 \mu \mathrm{m}$ thickness by use of LINTEC Corporation Universal Coating System. After blends were dried at $90^{\circ} \mathrm{C}$ for $2 \mathrm{~min}$, which were laminated with the release liner. These samples were seasoned at $23 \pm 3^{\circ} \mathrm{C}$ and $65 \pm 5 \% \mathrm{RH}$ for more than 7 days. The blends have $30 \mu \mathrm{m}$ thickness in their dry state.

\section{Measurements}

Measurement of the PSA properties, such as peel adhesion, tack and holding power, obeyed JIS-Z0237. The peel adhesion to stainless steel of blends samples was carried out in $180^{\circ}$ with a Toyo Balldwin Co., Ltd. TENSIRON/UTM4-100. The tack was measured by means of the J. Dow ball tack and the probe tack. Both the ball and the probe were made of stainless steel. These measurements were performed at $23^{\circ} \mathrm{C}$. The holding power of blend samples were
Table I. Surface tension of liquids $\left(\mathrm{dyn} \mathrm{cm}^{-1}\right)$

\begin{tabular}{lc}
\hline \multicolumn{1}{c}{ Liquid } & $\gamma_{\mathrm{L}}$ \\
\hline$n$-Undecane & 24.7 \\
$n$-Dodecane & 25.4 \\
$n$-Tetradecane & 26.7 \\
$n$-Hexadecane & 27.6 \\
trans-Decalin & 29.9 \\
cis-Decalin & 32.2 \\
\hline
\end{tabular}

measured with stainless steel using a Nitto Rika Kogyo Co., Ltd. NDC-100S creep tester at $40^{\circ} \mathrm{C}$.

The surface morphology on the blends of PEA with P(VDF-HFA) was studied by scanning electron microscopy (SEM). The surface on the blend samples was treated by vacuum evaporation with $\mathrm{Au}$, using Eiko Engineering Co., Ltd. IB-3 Ion Coater. The surface of blend samples was observed by use of Hitachi, Ltd. S-430 type SEM.

The critical surface tensions $\gamma_{c}$ of blends were estimated with the contact angle method. The contact angles of various liquids on the blend samples were performed by Kyowa Kaimen Kagaku Co., Ltd. CA-D system. The about $1.5 \sim 2.0 \mathrm{~mm}$ diameter drops of liquids were prepared by use of the microsyringe, which were dropped on the surface of blend samples. The surface tensions of liquids $\gamma_{L}$ used in contact angle measurement are shown in Table I.

The dynamic mechanical properties of the PEA/P(VDF-HFA) blends were carried out with the shearing method by means of Rheometrics Co., Ltd. RDS-II. The section areas and thickness of blend samples were $8 \mathrm{~mm} \phi$ and $6 \mathrm{~mm}$, respectively. The frequency and the heating rate were $1 \mathrm{~Hz}$ and $5^{\circ} \mathrm{C} \cdot \mathrm{min}^{-1}$, respectively. The initial strain was $0.1 \%$. The dynamic mechanical properties, such as the storage modulus $G^{\prime}$, the loss modulus $G^{\prime \prime}$ and the dynamic loss tangent $\tan \delta$ were measured in the range of -20 to $100^{\circ} \mathrm{C}$. 


\section{RESULTS AND DISCUSSION}

\section{PSA Properties}

In the blends of PEA with P(VDF-HFA), the results of PSA properties are shown in Table II. The $180^{\circ}$ peel adhesion, the J. Dow ball tack and the probe tack decreases with increasing the P(VDF-HFA) content. On the other hand, the holding power increases with increasing P(VDF-HFA) content in blends. It is presumed that the advances of holding power is influenced by the P(VDF-HFA) with the heating resistance (high modulus). We consider that the PSA properties of PEA can be controlled by blending the P(VDF-HFA) component.

\section{Morphology}

The PSA properties were seldom evaluated with the morphology (miscibility) of the adhesive surface. Recently, Kawahara and Akiyama ${ }^{19,20}$ developed the new adhesives by use of the poly(vinyl ethylene-co-1,4-butadiene) (V-BR). They also investigated the PSA properties, the miscibility and the morphology in blends of V-BR with various tackifier resins. The blends of V-BR with $70.4 \mathrm{wt} \%$ vinyl content and Gumrosin $\mathrm{X}$ were excellent adhesives and exhibited lower critical solution temperature LCST type phase diagram. They said $^{20}$ that the phase dispersed structure (morphology) on the PSA surface provided the information of adhesive mechanism.

The miscibility of blends observed by the electron microscope are reported by the several investigators. ${ }^{21-24}$ Akiyama and Kaneko have studied the morphology on the blends of poly(vinyl nitrate) PVN with poly(vinyl acetate) $\mathrm{PVAc}^{22}$ and poly(ethylene-co-vinylacetate) $\mathrm{EVAc}^{23}$ by use of the phase-contrast electron microscope. They pointed out that the PVN/PVAc and the PVN/EVAc blends were miscible because the $\approx 10 \mathrm{~nm}$ dispersive particles were not observed on these blends. Kaplan $^{24}$ studied the relationship between the dynamic mechanical property and the morphology of the blends. He concluded that the double peaks (immiscible) of the dynamic mechanical property corresponded to the appearance of dispersed particles above $15 \mathrm{~nm}$ diameter on the blends.

The SEM photograph of the PEA/P(VDFHFA) blend with the P(VDF-HFA) content 50 $(w t \%)$ is shown in Figure 1. No dispersive particles above $10 \mathrm{~nm}$ diameter were observed in the SEM photographs. The morphology of other blends was similar to that of blend with $50 \mathrm{wt} \% \mathrm{P}(\mathrm{VDF}-\mathrm{HFA})$ content. It is presumed that the blends of PEA with P(VDF-HFA) indicate the miscible system at room tempera-

Table II. Adhesive properties of PEA/P(VDF-HFA) blends

\begin{tabular}{ccccccc}
\hline $\begin{array}{c}\text { P(VDF-HFA) Content } \\
(\mathrm{wt} \%)\end{array}$ & 0 & 10 & 20 & 30 & 40 & 50 \\
\hline $\begin{array}{c}180^{\circ} \text { peel adhesion } \\
(\mathrm{g} / 25 \mathrm{~mm})\end{array}$ & 1300 & 1200 & 920 & 520 & 65 & 23 \\
\hline J. Dow ball tack & 4 & 2 & $2>$ & $2>$ & $2>$ & $2>$ \\
\hline Probe tack (g/5 mm $)$ & 416 & 338 & 156 & 73 & 42 & 9 \\
\hline Holding power $(\mathrm{min})$ & $\mathrm{CF}$ & $\mathrm{CF}$ & $\mathrm{NC}$ & $\mathrm{NC}$ & $\mathrm{NC}$ & $\mathrm{NC}$ \\
& 235 & 981 & $>1167$ & $>1167$ & $>1167$ & $>1167$ \\
\hline
\end{tabular}

a Dwell time, 24 hours.

$\mathrm{CF}$, cohesive failure of adhesive layer.

$\mathrm{NC}$, non creep. 


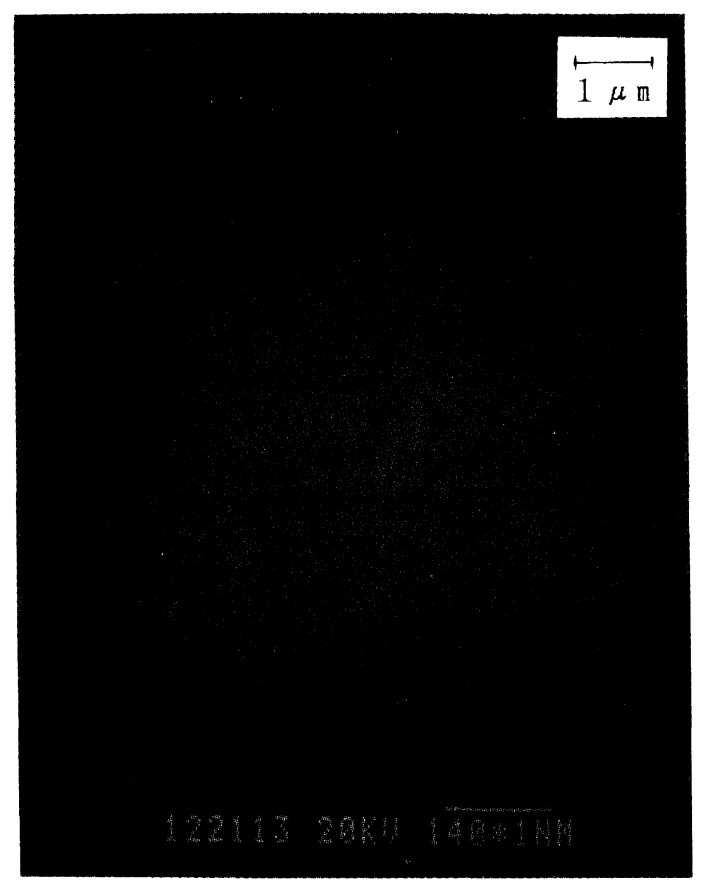

Figure 1. Scanning electron microscopy SEM photograph of PEA/P(VDF-HFA) blend with 50 (wt \%) P (VDF-HFA) content.

ture and the PSA properties are not affected by the surface morphology on these blend samples. The blends of P(VDF-HFA) with several polymers have exhibited LCST phase diagram; for example, the blends of P(VDFHFA)/poly(methyl methacrylate) $\mathrm{PMMA}^{5}$ and $\mathrm{P}(\mathrm{VDF}-\mathrm{HFA}) / \mathrm{EVAc}^{6}{ }^{6}$ If the PEA/P(VDFHFA) blends exhibit the LCST type phase diagram, the effect of the miscibility and the immiscibility on the PSA properties will be evaluated on around the LCST critical temperature.

\section{Critical Surface Tension}

It was reported ${ }^{25-27}$ that the PSA properties were influenced by the surface tension. Toyama et $a .^{25,26}$ measured the probe tack of the natural rubber/tackifier blends, the acrylic adhesives and the vinyl ether adhesives to various substrates. The critical surface tensions $\gamma_{\mathrm{C}}$ of the substrates had in the range of 20 to
$40 \mathrm{dyn}^{-1}$. They found that the maximum value of probe tack appeared around the $\gamma_{\mathrm{C}}$ of substrate nearly to that of adhesives. Dyckerhoff $^{27}$ also said that the maximum value of the adhesive strength for steel-adhesive system was exhibited in the peel strength vs. the surface tensions of the various treated steels plot. These results show the effects of $\gamma_{C}$ on the PSA properties.

Zisman $^{28,29}$ examined the contact angles $\theta$ of the surface of several polymers with the organic liquids. He pointed out that the relationship between the $\cos \theta$ and the surface tensions of the various liquids $\gamma_{L}$ lie on the good straight line, and determined the critical surface tension $\gamma_{C}$ which was the $\gamma_{L}$ value at $\cos \theta=1$ by extrapolating the straight line. Since, then, several researchers ${ }^{30,31}$ have evaluated $\gamma_{C}$ with the contact angle method, which has been analyzed by the various plots of the contact angle $\cos \theta$ and $\gamma_{L}$.

Recently, Saito ${ }^{32}$ proposed a new equation between the $\cos \theta$ and the $\gamma_{L}$, which has been expressed by the interfacial interaction of solid-liquid as follows

$\log (1+\cos \theta)=-\psi \cdot \log \left(\gamma_{\mathrm{L}}\right)+\log \left(2 \Phi_{0} \cdot \gamma_{\mathrm{S}}{ }^{0.5-\mathrm{a}}\right)$

where the parameters (a) is defined as the slope $(\psi)=(0.5-a)$ in the $\log (1+\cos \theta)$ vs. $\log \left(\gamma_{\mathrm{L}}\right)$ plot, $\gamma_{C}$ is estimated by the $\gamma_{L}$ value at $\log (1+\cos \theta)=\log (2)$ by extrapolating the straight line and $\Phi_{0}$ corresponds to a GoodGirifalco's parameter $\Phi_{\mathrm{G}}{ }^{33}$ and is expressed by the following equation.

$$
\Phi_{0}=\left(X_{\mathrm{L}}{ }^{\mathrm{d}} \cdot X_{\mathrm{S}}{ }^{\mathrm{d}}\right)^{0.5}+\left(X_{\mathrm{L}}^{\mathrm{p}} \cdot X_{\mathrm{S}}^{\mathrm{p}}\right)^{0.5}
$$

The $X_{j}^{\mathrm{d}}$ and $X_{j}^{\mathrm{p}}$ denote the dispersion and the polarity of the $j$ component, respectively. The polarity $X_{\mathrm{S}}^{\mathrm{p}}$ is obtained from the solubility parameter $\delta$ and the polarity component of solubility parameter $\delta^{\mathbf{p}}$ according to the next equation. $^{34}$

$$
X_{\mathrm{S}}^{\mathrm{p}}=\left(\delta^{\mathrm{p}} / \delta\right)^{2}
$$

We carried out the plot of $\log (1+\cos \theta) v s$. 
$\log \left(\gamma_{\mathrm{L}}\right)$ for the P(VDF-HFA $)^{35}$ and the blends of poly(vinylethylene-co-1,4-butadiene) ${ }^{36}$ with terpene resins. We found that the $\log (1+\cos \theta)$ $v s . \log \left(\gamma_{\mathrm{L}}\right)$ plot exhibited the good straight line than the Zisman plot and revealed the reasonable critical surface tension $\gamma_{\mathrm{C}}$.

The $\log (1+\cos \theta)$ vs. $\log \left(\gamma_{L}\right)$ plots obtained by the measurements of contact angles of the various dispersion liquids on the PEA/P(VDFHFA) blends, with the P(VDF-HFA) content 10 and $30 \mathrm{wt} \%$, are shown in Figure 2. The plot of $\log (1+\cos \theta)$ and $\log \left(\gamma_{L}\right)$ in Figure 2 lie on the good straight line, and the reasonable
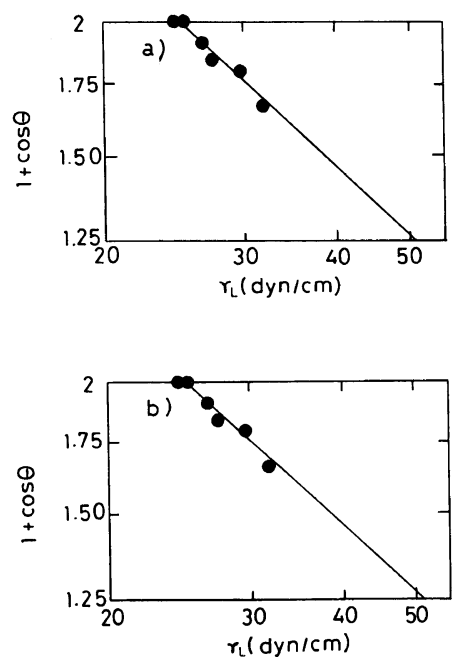

Figure 2. The $\log (1+\cos \theta)$ vs. $\log \left(\gamma_{\mathrm{L}}\right)$ plot of PEA/ P(VDF-HFA) blends. Content of the P(VDF-HFA) is as follows (wt \%): a) 10; b) 30 .

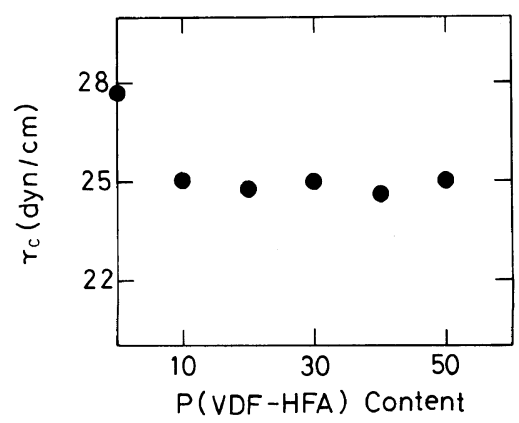

Figure 3. Relationship between the critical surface tension $\gamma_{\mathrm{c}}$ and P(VDF-HFA) content of PEA/P(VDFHFA) blends. critical surface tensions $\gamma_{C}$ are obtained by the value of $\gamma_{L}$ at $\log (1+\cos \theta)=\log (2)$ by extrapolating the straight line. The $\gamma_{C}$ of the PEA/P(VDF-HFA) blends with 10 and $30 \mathrm{wt} \%$ P(VDF-HFA) content exhibited about the same values from the $\log (1+\cos \theta) v s$. $\log \left(\gamma_{\mathrm{L}}\right)$ plot. The relationship between the $\gamma_{\mathrm{C}}$ for the PEA/P(VDF-HFA) blends and the $\mathrm{P}(\mathrm{VDF}-\mathrm{HFA})$ content are shown in Figure 3. The $\gamma_{\mathrm{C}}$ of PEA and the other blend samples are found to be $\approx 28 \mathrm{dyn} \mathrm{cm}^{-1}$ and $\approx 25 \mathrm{dyn}$ $\mathrm{cm}^{-1}$, respectively. Therefore, we consider the effect of surface tension on the PSA properties can be neglected for these blend systems.

\section{Dynamic Mechanical Properties}

The relationship between the PSA properties and the dynamic mechanical properties has been already investigated. ${ }^{37-39}$ Dahlquist $^{37}$ said that the tackiness of PSA appeared in the creep compliance of the bulk [is effective at a value of more than $1 \times 10^{-6} \mathrm{~cm}^{2} \mathrm{dyn}^{-1}$ for $1 \mathrm{~s}$ ]. Kraus and co-workers ${ }^{38,39}$ studied the effect of the loss modulus $G^{\prime \prime}$ on the probe tack for the block co-polymers in styrene with both isoprene and butadiene. They found that the maximum value of probe tack was exhibited around $G^{\prime \prime} \approx 1 \times 10^{6} \mathrm{dyn} \mathrm{cm}^{-2}$ in bulk. Thus, it was suggested that the value of PSA properties could be evaluated with dynamic

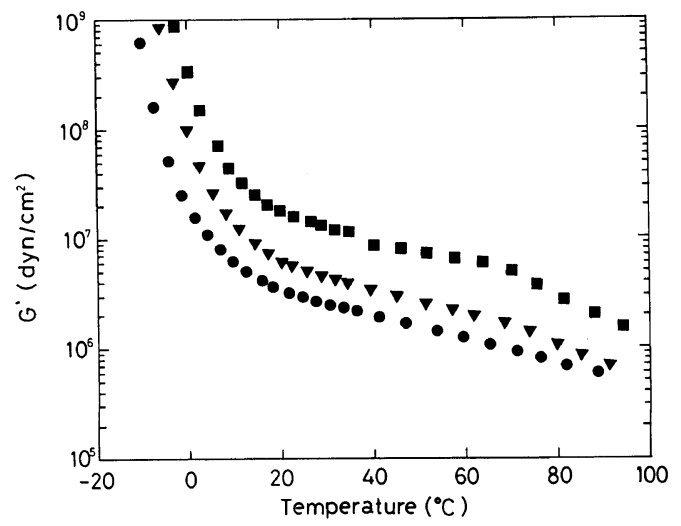

Figure 4. Temperature dependence of the storage modulus $G^{\prime}$ of PEA/P(VDF-HFA) belnds. Content of the $\mathrm{P}(\mathrm{VDF}-\mathrm{HFA})$ is as follows (wt $\%): 0,0 ; \nabla, 20 ; \mathbf{\square}, 40$. 
mechanical properties. In the blends of PEA with P(VDF-HFA), it is expected that the dynamic mechanical properties is especially effective against the PSA properties because the morphology and the $\gamma_{C}$ of these blends are changeless.

The storage modulus $G^{\prime}$ of the PEA/P(VDFHFA) blends as shown in Figure 4 decreases with rising temperature, which increases with increasing $\mathrm{P}$ (VDF-HFA) content in the blends. The delineation of the curve of the loss modulus $G^{\prime \prime} v s$. temperature is similar to that of the $G^{\prime}$ $v s$. temperature as shown in Figure 5. The temperature dependence of the dynamic loss $\operatorname{tangent} \tan \delta$ is shown in Figure 6. The maximum point of $\tan \delta$ shifts toward higher temperature side with increasing of the P(VDF-HFA) content, which relates to the

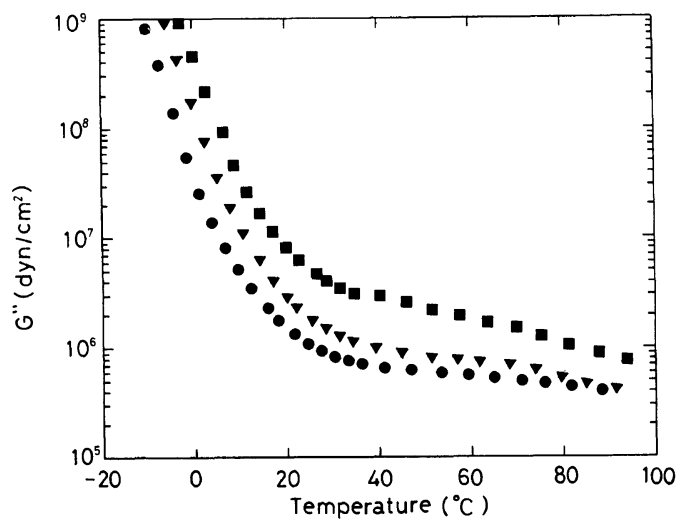

Figure 5. Temperature dependence of the loss modulus $G^{\prime \prime}$ of PEA/P(VDF-HFA) blends. Content of the $\mathrm{P}(\mathrm{VDF}-\mathrm{HFA})$ is as follows (wt $\%):-0 ; \nabla, 20 ; \square, 40$. glass transition temperature $T_{\mathrm{g}}$. In general, the $T_{\mathrm{g}}$ of the blends can be estimated with Fox's equation $^{40}$ as follows

$$
1 / T_{\mathrm{g}}=W_{1} / T_{\mathrm{g} 1}+W_{2} / T_{\mathrm{g} 2}
$$

where $W_{1}$ and $W_{2}$ are the weight fractions of components in the blend, $T_{\mathrm{g} 1}$ and $T_{\mathrm{g} 2}$ are the glass transition temperatures of the polymers. The $T_{\mathrm{g}}$ of the P(VDF-HFA) calculated by use of eq. 4 lies near $10^{\circ} \mathrm{C}$. In Figure 6 , the curve of $\tan \delta$-temperature for the PEA/ $\mathrm{P}(\mathrm{VDF}-\mathrm{HFA})=60 / 40$ blend shows the shoulder peak $\approx 40^{\circ} \mathrm{C}$. Maeda et al. ${ }^{4}$ confirmed that the P(VDF-HFA) [HFA content; $6.5(\mathrm{~mol} \%)$ ] is the crystal polymer and has the melting point $T_{\mathrm{m}}$ around $140^{\circ} \mathrm{C}$ by differential scanning calorimetry (DSC). It is well known that crystal polymer possesses $\alpha$-transition between $T_{\mathrm{g}}$ and

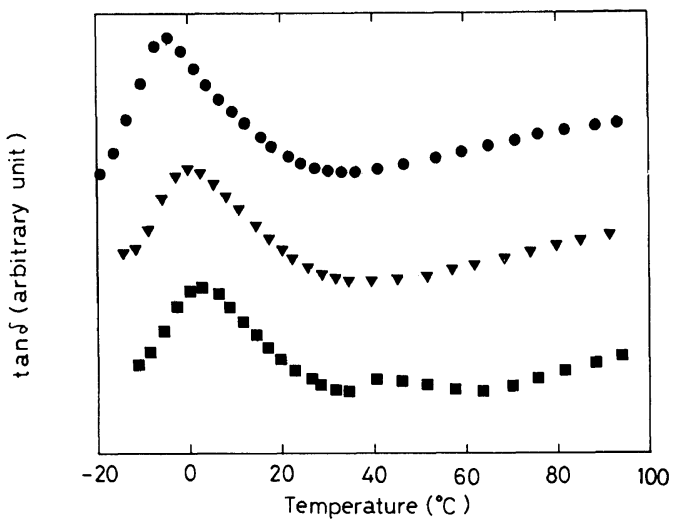

Figure 6. Temperature dependence of the dynamic loss tangent $\tan \delta$ ố PEA/P(VDF-HFA) blends. Content of the P(VDF-HFA) is as follows (wt \%):, $0 ; \nabla, 20 ; \square, 40$.

Table III. Viscoelastic properties at $23^{\circ} \mathrm{C}$ and glass transition temperature $\left(T_{\text {Dmax }}\right)$ of PEA/P(VDF-HFA) blends

\begin{tabular}{ccccccc}
\hline $\begin{array}{c}\text { P(VDF-HFA) Content } \\
(\mathrm{wt} \%)\end{array}$ & 0 & 10 & 20 & 30 & 40 & 50 \\
\hline$G^{\prime} \times 10^{-6}\left(\mathrm{dyn} \mathrm{cm}^{-2}\right)$ & 3.20 & 3.65 & 5.54 & 7.58 & 15.8 & 23.9 \\
\hline$G^{\prime \prime} \times 10^{-6}\left(\mathrm{dyn} \mathrm{cm}^{-2}\right)$ & 1.34 & 1.44 & 2.35 & 3.21 & 6.10 & 9.10 \\
\hline$T_{\text {Dmax }}\left({ }^{\circ} \mathrm{C}\right)^{\mathrm{a}}$ & -4.3 & -2.1 & -0.3 & 1.6 & 2.6 & 3.7 \\
\hline
\end{tabular}

a Maximum temperature of $\tan \delta$. 
$T_{\mathrm{m}}$. Therefore, it is predicted that the shoulder peak of the PEA/P(VDF-HFA) blend with the $40 \mathrm{wt} \%$ P(VDF-HFA) content corresponds to the $\alpha$-transition temperature.

The dynamic mechanical properties $\left(G^{\prime}, G^{\prime \prime}\right)$ at $23^{\circ} \mathrm{C}$ and the $T_{\text {Dmax }}$ (the maximum value of $\tan \delta$ ) for the PEA/P(VDF-HFA) blends are shown in Table III. The value of these properties increases monotonically with increasing $\mathrm{P}(\mathrm{VDF}-\mathrm{HFA})$ content in the PEA/ $\mathrm{P}$ (VDF-HFA) blends. It is expected that the dynamic mechanical properties affects to the PSA properties. The relationship between the $180^{\circ}$ peel adhesion and both the $G^{\prime}$ and $G^{\prime \prime}$ at $23^{\circ} \mathrm{C}$ for the PEA/P(VDF-HFA) blends are shown in Figure 7. The $180^{\circ}$ peel adhesion decreases with increasing $G^{\prime}$ and $G^{\prime \prime}$. The value of the $180^{\circ}$ peel adhesion is influenced by the contact area $S_{\mathrm{a}}$ of the adhesive and substrate, which increases with decreasing critical surface tension $\gamma_{\mathrm{C}}$, the $G^{\prime}$ and the $G^{\prime \prime}$ of adhesive. ${ }^{41}$ The $S_{\mathrm{a}}$ is also responsible to the phase dispersed structure on the adhesive surface. ${ }^{36}$

In this study, the $\gamma_{C}$ and the morphology of the PEA/P(VDF-HFA) blends unchanged with the blend content. Thus, it is suggested that the $180^{\circ}$ peel adhesion for blends of PEA with P(VDF-HFA) is especially affected by the dynamic mechanical properties $\left(G^{\prime}, G^{\prime \prime}\right)$. The value of probe tack of the PEA/P(VDF-HFA) blends decreases with increasing $G^{\prime}$ and the $G^{\prime \prime}$ as well as the $180^{\circ}$ peel adhesion as shown in

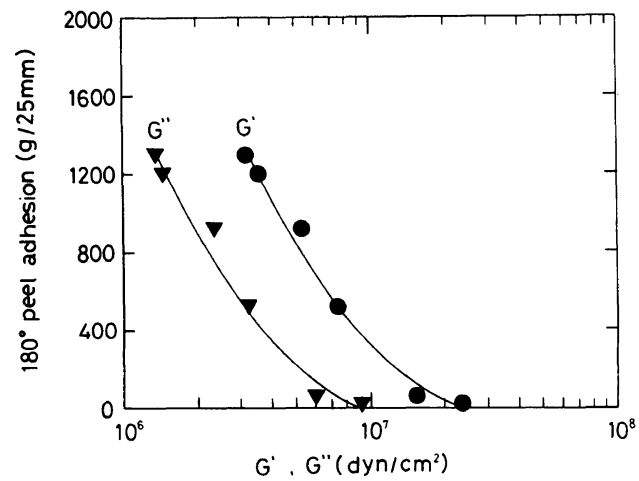

Figure 7. Relationship between the $180^{\circ}$ peel adhesion and both storage modulus $G^{\prime}$ and loss modulus $G^{\prime \prime}$ at $23^{\circ} \mathrm{C}$.
Figure 8 . It is presumed that the probe tack is also influenced by the viscoelastic properties $\left(G^{\prime}, G^{\prime \prime}\right)$, enormously. The values of J. Dow ball tack for the PEA/P(VDF-HFA) blends above $20 \mathrm{wt} \% \mathrm{P}(\mathrm{VDF}-\mathrm{HFA})$ content exhibit less 2. It is considered that the evaluation of tackiness by the J. Dow ball tack is difficult compared to that of tackiness by probe tack. The $T_{\text {Dmax }}$ of the PEA/P(VDF-HFA) blends as shown in Table III changes by about $8^{\circ} \mathrm{C}$ with $\mathrm{P}(\mathrm{VDF}-\mathrm{HFA})$ content in the range of 0 to $50 \mathrm{wt} \%$. In general, it has been reported that the PSA properties depend on the $T_{\text {Dmax }}$ in the poly(vinylethylene-co-1,4-butadiene)/ terpene blends, ${ }^{42}$ the copolymers of 2ethylhexyl acrylate and acrylic acid. ${ }^{41}$ The relationship between the $T_{\mathrm{Dmax}}$ and both the

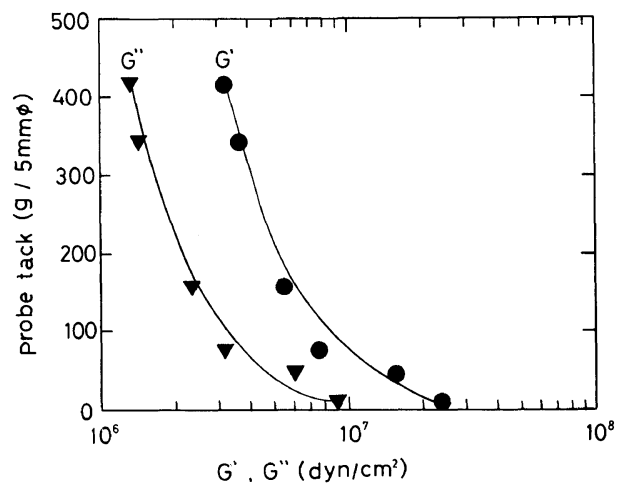

Figure 8. Relationship between the probe tack and both storage modulus $G^{\prime}$ and loss modulus $G^{\prime \prime}$ at $23^{\circ} \mathrm{C}$.

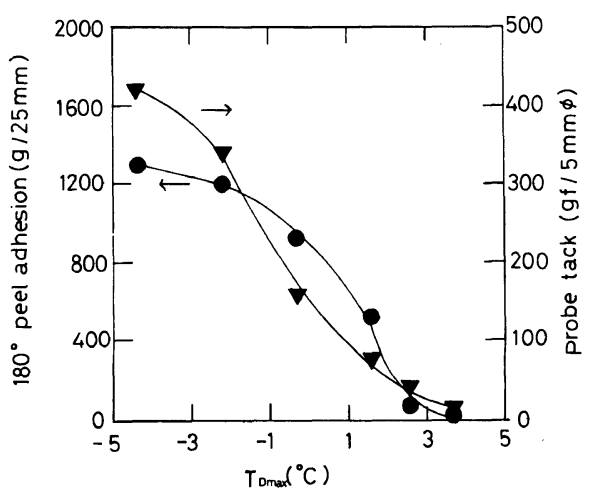

Figure 9. Effect of the glass transition temperature $\left(T_{\text {Dmax }}\right)$ on $180^{\circ}$ peel adhesion and probe tack. 
$180^{\circ}$ peel adhesion and probe tack are shown in Figure 9. The $180^{\circ}$ peel adhesion and probe tack decrease with increasing the $T_{\text {Dmax }}$ of the blends. The flow of the adhesive onto substrate is lost at the temperature above $T_{\mathrm{g}}$ because the polymer segment is freezed at $T_{\mathrm{g}}$. Empirically, it is said that the tack $\approx 0$ of the adhesive is in $\approx T_{\mathrm{g}}+20^{\circ} \mathrm{C}$ (critical tack temperature). ${ }^{43} \mathrm{We}$ presume that the $180^{\circ}$ peel adhesion and the probe tack increase remarkably with decreasing $T_{\text {Dmax }}$ because the blend with $50 \mathrm{wt} \% \mathrm{P}(\mathrm{VDF}-$ HFA) content is nearly the critical tack temperature. It may be expected that the $180^{\circ}$ peel adhesion and the probe tack are influenced by the micro segmental motion of the bulk. Therefore, in the blends of PEA with P(VDF-HFA), it is thought that the $180^{\circ}$ peel adhesion and the probe tack can be estimated with the dynamic mechanical properties, such as $G^{\prime}, G^{\prime \prime}$, and $T_{\mathrm{Dmax}}$. Excellent holding power of the PEA/P(VDF-HFA) blends represented in Table II was found in the blend samples above $20 \mathrm{wt} \% \quad \mathrm{P}(\mathrm{VDF}-\mathrm{HFA})$ content. In general, the holding power is influenced by the molecular weights and the modulus for the adhesive. We consider that the holding power of the PEA/P(VDF-HFA) blends are affected by the P(VDF-HFA) component possessing the high modulus and the remarkable heating resistance.

From these results, we concluded that the PSA's properties, such as the adhesion, the tackiness and the holding power, can be evaluated with the $G^{\prime}, G^{\prime \prime}$, and $T_{\mathrm{Dmax}}$ in the PEA/P(VDF-HFA) blends. Moreover, it is expected that the blends of PEA with P(VDF-HFA) can be utilized as new adhesives.

\section{CONCLUSION}

In PEA/P(VDF-HFA) blends, the pessure sensitive adhesive properties, the surface morphology, the critical surface tension $\gamma_{C}$ and the dynamic mechanical properties were investigated. The following results were ob- tained.

1) The new adhesives were made from the mixtures of the PEA with P(VDF-HFA).

2) The $180^{\circ}$ peel adhesion and tackiness decreased with increasing P(VDF-HFA) content in blends.

3) The holding power increased with increasing P(VDF-HFA) content.

4) The morphology observed by SEM and the $\gamma_{C}$ obtained by means of the contact angle method were changeless in these blends.

5) The dynamic mechanical properties $\left(G^{\prime}\right.$, $\left.G^{\prime \prime}\right)$ and the $T_{\text {Dmax }}$ increased with increasing P(VDF-HFA) content.

6) It was suggested that the PSA's properties were affected by the $G^{\prime}, G^{\prime \prime}$, and $T_{\text {Dmax }}$ in the PEA/P(VDF-HFA) blends.

Consequently, we consider that the PSA properties in the blends of PEA with P(VDF-HFA) could be controlled with the behaviors of the dynamic mechanical properties. However, it is expected the PSA properties may be affected by surface morphology and $\gamma_{C}$ in other polymer blends. Thus, the interpretation of the effects of the morphology and $\gamma_{C}$ on the PSA's properties is necessary for investigating the pressure sensitive adhesive properties and now be conducted.

Acknowledgments. The authors express their sincere thanks to Mr. S. Kawahara for valuable instruction and to Central Glass Co., Ltd. for supplying the fluoro-copolymer.

\section{REFERENCES}

1. M. A. Krenceski, J. F. Johnson, and S. C. Temin, Macromol. Chem. Phys., C26, 143 (1986).

2. K. Fukuzawa, "Nenchaku Gijutsu," Kobunshi Kankokai, 1987.

3. "Nenchakuseihin no Oyogijutsu," CMC Press, Tokyo, (1989) (in Japanease).

4. K. Maeda, T. Yamauchi, and K. Tsutsumi, Polym. J., 22, 381 (1990).

5. S. Kobayashi, S. Tasaka, and S. Miyata, Kobunshi Ronbunshu, 44, 695 (1987).

6. M. Hasegawa and S. Akiyama, Polym. J., 20, 471 (1988). 
7. S. Akiyama and Y. Hashimoto, Bull. Fac. Gen. Educ. Tokyo Univ. Agric. \& Tech., 23, 79 (1988).

8. Y. Kano and S. Akiyama, Nippon Setchaku Gakkaishi, 26, 173 (1990).

9. Y. Kano, K. Ishikura, and S. Akiyama, Nippon Setchaku Gakkaishi, 26, 252 (1990).

10. Y. Kano, S. Kamagami, and S. Akiyama, Nippon Setchaku Gakkaishi, 26, 284 (1990).

11. Y. Kano and S. Akiyama, Nippon Setchaku Gakkaishi, 26, 367 (1990).

12. Y. Kano, S. Kawahara, and S. Akiyama, Nippon Setchaku Gakkaishi, 27, 86 (1991).

13. Y. Kano, K. Ishikura, S. Kawahara, and S. Akiyama, Polym. J., in press.

14. D. Satas, "Handbook of Pressure Sensitive Adhesive Technology," 2nd ed, Van Nostrand Reinhold, New York, 1989.

15. D. W. Aubrey, Rubber. Chem. Tech., 61, 448 (1987).

16. S. Akiyama, Nippon Setchaku Kyokaishi, 20, 485 (1984).

17. T. Saito, Nippon Setchaku Kyokaishi, 21, 228 (1985); ibid., 21, 275 (1985).

18. J. Furukawa, Nippon Setchaku Kyokaishi, 24, 403 (1988).

19. S. Kawahara and S. Akiyama, Nippon Setchaku Gakkaishi, 26, 142 (1990).

20. S. Kawahara and S. Akiyama, Polym. J., 23, 47 (1991).

21. S. Kawahara, S. Akiyama, and A. Ueda, Polym. J., 21, 221 (1989).

22. S. Akiyama, N. Inaba, and R. Kaneko, Kobunshi Kagaku, 26, 529 (1969).

23. S. Akiyama and R. Kaneko, Kobunshi Ronbunshu, 31, 12 (1974).

24. D. Kaplan, J. Appl. Polym. Sci., 20, 2615 (1976).

25. M. Toyama, T. Ito, H. Nukatsuda, and M. Ikeda, $J$. Appl. Polym. Sci., 17, 3495 (1973).

26. M. Toyama, T. Ito, and H. Moriguchi, J. Appl. Polym. Sci., 14, 2039 (1970).
27. G. A. Dyckerhoff and P. J. Sell, Angew. Macromol. Chem., 21, 169 (1972).

28. H. W. Fox and W. A. Zisman, J. Colloid. Sci., 5, 514 (1950); ibid., 7, 109 (1952); ibid., 7, 428 (1952).

29. W. A. Zisman, "Contact Angle, Wettability and Adhesion," American Chemical Society, Washington, D.C., 1964, pp 1-51.

30. D. H. Kaelble and K. U. Uy, J. Adhesion, 2, 50 (1970).

31. Y. Kitazaki and T. Hata, Nippon Setchaku Kyokaishi, 8, 131 (1972).

32. T. Saito, Nippon Setchaku Kyokaishi., 24, 347 (1988); ibid., 24, 431 (1988); ibid., 24, 469 (1988).

33. a) L. A. Girifalco and R. J. Good, J. Phys. Chem., 61, 904 (1957).

b) R. J. Good and L. A. Girifalco, J. Phys. Chem., 64, $541(1960)$.

c) R. J. Good, "Contact Angle, Wettability and Adhesion," American Chemical Society, Washington, D.C., 1964, p 99.

34. S. Wu, "Polymer Interface and Adhesion," Marcel Dekker Inc., New York, 1982, p 105.

35. Y. Kano, S. Akiyama, Polymer, in press.

36. S. Kawahara, Y. Kano, and S. Akiyama, Polym. J., in press.

37. C. A. Dahlquist, Adhesives Age, 10, 25 (1959).

38. G. Kraus, "Rheological Characteristics and Performance of Block Polymer Based Pressure Sensitive Adhesives," TAPPI Hot-Melt Short Course, Junel-4, 1980, pp 79-85.

39. G. Kraus, F. B. Jones, O. L. Marrs, and K. W. Rollman, J. Adhesion, 8, 235 (1977).

40. T. G. Fox, Bull. Am. Phys. Soc. (Ser 2), 1, 123 (1956).

41. Y. Kano, S. Akiyama, Polymer, submitted.

42. S. Kawahara, S. Akiyama, and Y. Kano, Polymer, 32, 1681 (1991).

43. M. Toyama, "Kanatsu Setchakuzai (Nenchakuzai)," Kobunshi Kankokai, Kyoto, 1991. 